\title{
Fostering Integrated Learning and Faculty Collaboration through Curriculum Design: A Case Study
}

\author{
Robert L. Routhieaux ${ }^{1, *}$ \\ ${ }^{1}$ School of Business, Hamline University, MS-A1740, 1536 Hewitt Ave, Saint Paul, MN 55104, USA \\ *Correspondence: School of Business, Hamline University, MS-A1740, 1536 Hewitt Ave, Saint Paul, MN 55104, \\ USA. Tel: 1-651-523-2642
}

Received: January 27, 2015

Accepted: March 19, $2015 \quad$ Online Published: May 7, 2015

doi: $10.5430 /$ jct.v4n 1 p 122

URL: http://dx.doi.org/10.5430/jct.v4n1p122

\begin{abstract}
Designing and implementing innovative curricula can enhance student learning while simultaneously fostering faculty collaboration. However, innovative curricula can also surface numerous challenges for faculty, staff, students, and administration. This case study documents the design and implementation of an innovative Master of Business Administration (MBA) program at a comprehensive university located in a metropolitan area in the Midwestern United States. It outlines the successes and challenges encountered along the way, and provides suggestions regarding the development and implementation of innovative curricula.
\end{abstract}

Keywords: curriculum design; integration of learning; faculty collaboration

\section{Background/Context}

Several years ago, our School of Business began development of an innovative, integrative, modular-based MBA program. As a relative late entrant into the MBA market in the metropolitan region, we needed to develop a program that could be clearly differentiated from more than ten other existing MBA programs in the metro area. We created this differentiation through curriculum design and unique delivery methods.

The program was developed to address many of the most frequent critiques of existing MBA programs (Fisher, 2007; Mintzberg, 2005; Pfeffer \& Fong, 2002; Rubin \& Dierdorff, 2008), with special emphasis on integration of content from across the curriculum. Given the innovative design, we were able to quickly differentiate our program and attract hundreds of students. However, the format and delivery presented conflicts with many existing policies, procedures, and administrative processes. It also required levels of faculty engagement and collaboration uncommon in higher education.

The curriculum was designed to provide integration of various content areas from the beginning, and was based around four core knowledge areas related to business operations. The delivery moved away from the standard teaching format and teaching loads, utilizing faculty expertise in more focused and intensive means.

This unique design and delivery clearly met the need for differentiation. Within the first two and a half years, over 600 students enrolled in the program. This rapid growth was a blessing for the University, which had experienced the same enrolment challenges that have become common in higher education. The unprecedented growth of the program was a catalyst for instilling a positive environment and attracting new faculty. It also added to the challenges of offering a unique curriculum.

The opportunities and challenges faced can be classified in a number of ways. The following list provides an overview of some of these opportunities and challenges:

1. The program was designed around four integrated modules that did not fit into existing models and policies regarding faculty teaching.

2. The innovative and integrative design required faculty to coordinate their teaching efforts much more than the norm in higher education. 
3. Prospective students did not have clear bases for comparison since the design and delivery of the program was so vastly different than other MBA programs.

4. Prospective transfer students were difficult to address given the unique curriculum. Courses from other schools did not 'fit' directly into the program, and students could not transfer in individual elements of the modules.

5. The registration process for students was complicated given the design and delivery of the program.

6. The registration process was further complicated because the program operated year-round, and not in exact sequence with the standard semesters / terms of the school.

7. Implementing a cohort-based approach to the program created complications with students who needed to 'stop-out' for a semester or more.

8. Faculty needed to adapt to the increased need for communication and collaboration, resulting in confusion for students (and faculty) at many points throughout the program.

9. Administrative processes regarding student transcripts and records required significant changes from existing policies and procedures.

10. Financial aid and tuition reimbursement policies and procedures created a number of unique constraints that needed to be addressed.

11. Feedback loops needed to be developed at nearly every point throughout the program without clear precedent for doing so.

12. Students had the added challenge of explaining the innovative program to current or prospective employers.

While the above list focuses more on the challenges faced along the way, the reader should note that each of these challenges presented unique opportunities to adjust and improve policies and procedures. As most in academia will attest, universities are often slow to change, even when existing practices are in clear need of refinement and revision. The innovative MBA program provided a (somewhat) welcome catalyst for improving and streamlining processes and procedures. The clear success in terms of enrollment provided the much needed boost to dealing with all of the complications.

Along the way the University has learned many valuable lessons on designing and implementing innovative curricula. This report / case study will provide more detail on these experiences. The goal is to provide other schools that are contemplating or about to implement innovative curricula with some advanced knowledge on the issues that will arise and how they might be addressed.

The remainder of this report is divided into four main sections. The first section, Brief Review of the Literature, provides an overview of common critiques of MBA programs and how integrative curricula might address those critiques. The second section, Differentiation and Design, outlines the process and guiding principles we used in designing the new MBA program. The third section, Faculty Impacts and Adjustments, outlines the changes faculty needed to make in implementing / delivering the program. The fourth section, Feedback and Program Revision, outlines the feedback systems and some of the changes made in refining the program.

\section{Brief Review of the Literature}

\subsection{Common Critiques of MBA Programs}

The main critiques of MBA programs as a whole focus on two key concerns. The first is the over-emphasis on quantitative and financial skills at the expense of interpersonal and relationship skills (AACSB, 2006; Dvorak, 2007; Ewers, 2008; Fisher, 2007; Mintzberg, 2005; Rubin \& Dierdorff, 2008). Many authors have noted that communication and interpersonal skills are the cornerstones of truly successful executives and managers. Countless articles and popular press publications have expounded on the notion that at all levels of organizations, individuals with strong "soft skills" out-perform those with more limited interpersonal capabilities.

The second major critique is the overall lack of integration of knowledge, where students learn subjects in relative isolation of one another with only one or two courses aimed at integrating knowledge and skills (Chew \& McInnis-Bowers, 2004; Peters, 2006; Pfeffer \& Fong, 2002). The results of this lack of integration include limited skills in managing continuous change and inabilities to make sound decisions in uncertain contexts (AACSB, 2006). It was clear that our program should directly address these two common critiques of MBA programs. 
There are several other common critiques of MBA programs and other business school educational models. Jain \& Stopford (2011) point out that the common curricula for MBA programs have not changed significantly in nearly fifty years (p. 346). The primary focus on financial and analytical skills has stayed constant. Datar, Garvin \& Cullen (2010) note that many programs "offer the same mix of requirements, with coverage of many of the same topics" (p. 47). Most of the revisions to this framework have been through adding small components or stand-alone classes in "emerging" areas, like global understanding, cross-cultural communication, ethics, and innovation.

Several authors have critiqued MBA programs, and the schools that house them, for over-utilization of research focused faculty with limited practical business experience (AACSB, 2006; Jain \& Stopford, 2011; Pfeffer \& Fong, 2004). This disconnect leads to faculty with extensive book smarts, but limited capabilities in applying those smarts in a business setting (Datar, Garvin \& Cullen, 2010). Some schools try to address concern through balanced use of full time faculty (preferably with actual business experience) and part-time faculty that work full time in business.

\subsection{Potential Benefits of Innovative Curricula}

Innovative curricula can provide for a number of potential benefits. First, such curricula provide the context for integration of broad learning, moving beyond the traditional "silo" approaches to education (Ducoffe, Tromley \& Tucker, 2006; Malekzadah, 1998). In addition, innovative curricula can provide an intentional conduit for addressing other long standing program limitations, like those outlined in the section above.

Second, innovative and integrative curricula provide a foundation for, and create a strong need for, ongoing faculty development (Clark, 2005). Faculty members are often hired for their specialized knowledge within a field. Their educational journey is often marked by specialization in key areas, and often with limited training in adult education and human learning theory and application. Innovative curriculum design and implementation can provide a catalyst for faculty interaction and development around both business knowledge and pedagogy.

Third, innovative curricula provide a context for faculty, staff and administration collaboration. Given the many complex and interdependent factors of program design, student recruitment, registration and records, faculty contracts, and related issues, innovative curricula can help to foster cross functional communication. As stated by Clark (2005), "to be successful, innovative programs require an enthusiastic, supportive learning community" (p. 4). All too often, faculty, staff and administration have little interest or reason for true collaboration. Design and implementation of innovative curricula can provide a reason and means to break down these barriers and create a more collaborative culture and climate.

Finally, innovative curricula can help to differentiate an institution and program from the multitude of competitors for students. As the landscape for MBA programs continues to change and get more competitive (Datar, Garvin \& Cullen, 2010), attracting students often requires unique approaches and messages. While students clearly choose programs for non-curricular reasons (cost, location), in regions where there are many options for professional education - differentiation can be key.

\section{Differentiation and Design}

\subsection{Late Entry into Potentially Saturated Market}

The metropolitan region where the University is located is blessed with an abundance of high-quality colleges and universities. The region benefits in many ways, including strategic partnerships across public, private, nonprofit, and educational sectors, plus a highly regarded, well-educated workforce. This does, however, present challenges for colleges and universities as they must continually adapt to increased competition for students and tuition dollars.

This context was the starting point for the University in developing a Master of Business Administration (MBA) program. When we began reviewing existing programs, and upon the official launch of the MBA program, there were more than ten institutions offering MBA programs in the metropolitan region (ranging from full-time to executive to online programs). It was very clear we needed to do something different. Our goal was not to try to directly compete with other schools, but to find a way we could easily and clearly differentiate ourselves in what may have appeared a saturated market.

In our review of existing MBA programs in the region, we were struck by the relative consistency of program content and delivery across schools. While there are a few unique programs, our goal of finding a way to differentiate ourselves was only limited by our own creativity. We had the great benefit of starting from scratch in the design and delivery of our program. 


\subsection{Review of Innovative Approaches}

Of course, we did not want to venture off and create something innovative without tapping into the broad range of ideas throughout the world. We started by conducting research and needs analysis with local business professionals. These discussions, in one-on-one and larger group meetings, focused on the questions: "What key skills do you expect from prospective hires with MBA degrees, and what knowledge or skills have been most lacking in previously hired MBA's?" While responses varied quite a bit, the most common themes paralleled the critiques discussed above - limited focus on people skills and lack of integration. In addition, the business leaders emphasized that many newly hired MBA's were not adept at managing diverse groups of people, and did not have the political astuteness to navigate organizations and manage cross-division projects.

Next, we reviewed a wide variety of programs that specifically stated in their promotional and program literature a focus on "social skills" and "integration." We were pleased to find many examples of innovative programs in locations around the world. What became clear in this review was that the standard approach to MBA programs, with a core set of stand-alone classes along very traditional business disciplines, seemed to impede the need for innovation in design and delivery. Most of the innovative programs with strong focus on social skills and integration were delivered in a modular format - where different topics were clustered together and different disciplines were covered in differing credits and formats. In essence, these schools had done away with standard 3 or 4 credit courses taught by a single instructor.

The review of critiques of existing MBA programs and review of innovative curricula at other schools provided many valuable ideas for our new program. They provided context for a set of guiding principles used in developing and delivering a program that could be clearly differentiated from programs at other schools. (Note: Appendix A contains a list of schools that were particularly helpful in our review.)

\subsection{Guiding Principles and Common Themes}

The guiding principles used in the design of the program included:

1. Maintain focus on developing social skills, including interpersonal and communication skills, while still providing sufficient breadth and depth on critical quantitative and financial skills.

2. Foster integration of program content from the start, with continued emphasis on integration throughout the program.

3. While faculty and administrative constraints should be kept in mind, think well beyond existing formats and procedures.

These guiding principles were critical in making the new program a success. We realized, however, that these core guiding principles were only a starting point. It was clear we needed additional guidance in the form of an overall framework for our program, and a set of common themes that would help provide for integration throughout the program.

The overall framework for the program was based on curriculum development work by the author at other institutions. From past experiences running small businesses, working with nonprofit organizations, teaching entrepreneurship, and teaching nonprofit management, he had developed a basic framework for understanding and classifying "what you need to know to run a successful organization." These four core areas of knowledge included (brief descriptions of each of these core areas is listed in Appendix B):

1. Managing and leading people with integrity and purpose

2. Managing operations and leveraging organizational finances

3. Understanding external environments for long-term success / sustainability

4. Strategic change management and coordination of business functions

These four core knowledge areas became the basic building blocks of the program, and the overall focus of the four core Modules of the program. This design not only provided for integration of material within each module, but also helped in integrating material across modules.

To further foster development of social skills and integration, we also outlined a set of common themes that would be covered from a variety of perspectives throughout the program. These common themes included many areas identified in the literature as lacking in most MBA programs (Datar, Garvin \& Cullen, 2010; Jain \& Stopford, 2011; Pfeffer \& Fong, 2002; Rubin \& Dierdorff, 2008): 
- Communication - connecting with, informing, and influencing others through interpersonal, group and formal (written) communication strategies and methods

- Ethics - holistic understanding of human and environmental impact, values-driven decision making, transparency, and accountability for actions

- Global awareness - managing diverse employees, understanding international markets, leveraging international resources, developing multicultural teams

- Change - planning and implementing organizational growth and development, responding to crisis, developing flexible and adaptable people and organizations

- Conflict management - addressing immediate concerns while proactively and creatively addressing future uncertainties and opportunities

- Technology - utilizing current technologies and trends to enhance and maintain quality, efficiency, marketing, and human relations

- Critical and reflective analysis - looking beyond symptoms for root causes and situational constraints to organizational concerns and market development

These common themes provided an initial set of learning objectives for the development of the program. Our goal was to ensure that each of these themes would be covered in at least some ways in each of the four core modules of the program.

\subsection{Building on History and Reputation}

It should be noted that, while the University was a new entrant into the MBA market, it was not at all new to the area. Established well over one hundred years ago, the University has distinction as a pioneer among colleges and universities in the region, with a well established reputation in the region for providing excellent educational programs. We were able to build on this reputation in offering the new program, which certainly helped in our recruiting efforts.

It is also important to note that the development of the MBA program, with its focus on social skills and integration, was consistent with the University's history as a provider of top-notch liberal-arts based education. Our commitment to these ideals not only helped in attracting students, it also helped in getting the program approved within the university in a timely fashion. We also had experience with graduate business education prior to the launching of the MBA program, so we were already somewhat known in the market as a provider of graduate business education.

\subsection{Balancing Learning and Logistics}

In our planning and design, we decided that the four core modules of the program would be delivered in integrated 10 -credit blocks or modules that students would take sequentially. This format provided a good balance between the learning of our students and the need for some consistency in delivery and format. This balancing of learning and logistics has been an ongoing process. In fact, we are still in the process of finding an ideal balance along these lines.

From a student standpoint, learning and logistics seem to be inexorably intertwined. Their desire and need for learning is bound by a set of parameters that must be taken into account in the design and delivery of a program (Peters, 2006). This was no more apparent than in our discussions of our target market for the program.

Essentially, there are three key market segments for MBA programs: Full-time programs offered during the day, geared at younger students who either do not work or only work part-time; Part-time programs offered on nights and weekends, designed for early to mid-career professionals who work full-time; and Executive programs offered in unique formats, designed for mid to late-career professionals. In designing and launching the new program, we needed to be very clear as to which market we were aiming to capture (at least initially). Based on our faculty, physical resources, and our newness to the market, our initial target market was the early to mid-career professionals.

This group of potential students is pretty clear in terms of their parameters in searching for a program. What we knew from prior research and experience was that the large majority of this target market wanted to attend class only one night per week (with no or limited weekend classes) and to finish the program in two years or less. While school reputation, cost, and overall program design are important, program delivery outside of this narrow set of parameters will limit enrollment in even the best programs. These logistical concerns were critical to the successful launch and growth of the program, and influenced design and implementation accordingly.

Of course, balancing student demands regarding learning and logistics was only half of the balancing act in the design and implementation of the program. The other key group to consider was faculty. What was clear going in 
was that adherence to traditional teaching formats would not work, but that innovative design and delivery needed to address faculty constraints. This balance is the focus of the following section.

\section{Faculty Impacts and Adjustments}

\subsection{Moving Beyond Standard Teaching Loads}

Teaching loads are the cornerstone of faculty contracts, and one of the hallmark criteria that determine the major classifications of colleges and universities. At most institutions, faculty contracts stipulate a specific number of credits that are to be taught (at minimum) each year. Typically this entails a specific number of courses that are to be taught. These standard teaching loads then dictate course scheduling, and by default help in determining number of offerings, class size, and need for adjunct instructors.

The University is no different in this regard. At the University, the standard teaching load for full-time faculty is 24 credits per year. With nearly all classes being four credits, most full-time faculty members teach six courses per year (with some exceptions, of course). However, the new MBA program was not broken down into stand-alone, four credit courses. As outlined in the attached MBA Program Overview (see Appendix C), our program was initially broken down into Competencies that ranged from one to five credits. This breakdown resulted in faculty teaching loads that, while still based on a standard teaching load of 24 credits per year, did not result in a clear number of courses being taught.

This format also results in imbalanced teaching loads / assignments. For example, with Accounting being taught near the beginning of the second Module, Accounting faculty have a very strongly weighted teaching load at the beginning of each term (our program has three terms, Fall, Spring, and Summer), with very light load the second half of each term. This imbalance has great benefits for faculty, but also presents some challenges.

The benefits are that faculty responsibilities can be apportioned in bigger blocks than the norm. Instead of balancing teaching, scholarship, and service on a weekly basis, faculty can focus on teaching for several weeks or months and then focus on scholarship for several weeks or months (service seems to stay consistent regardless). Faculty members that teach in the MBA program seem to appreciate this different approach to scheduling.

The challenge has been the actual scheduling. Since Competencies do not all start and end at the same times, there is increased need for coordination of activities. To address this logistical challenge without over-burdening one individual with scheduling for all four core modules of the program, we created the role of Module Coordinator. These positions (a service commitment) are responsible for the scheduling of individual faculty for each of the respective Modules (we have run from two to five cohorts of each Module each term). This ongoing responsibility was extremely challenging at the beginning, as we were growing both full-time and part-time faculty ranks.

\subsection{Balancing Creativity and Consistency}

The second key opportunity / challenge regarding faculty was balancing faculty creativity and academic freedoms with the need for consistency across the program. With stand-alone classes, faculty can generally start from a defined set of learning objectives and then design courses to their strengths and interests. Our innovative curriculum, with its stated emphasis on integration, provides constraints on this approach. For program and learning consistency, it is important that that the materials for each section within each Module be the same, regardless of faculty teaching that Competency.

This approach creates the need for regular and consistent dialogue among faculty within each Module and Competency. To ensure this communication, we instituted monthly meetings of the Module Coordinators, and regular meetings for faculty who teach within each Module. These conversations focus on selection of readings, assignments / projects, use of guest speakers, delivery methods (including use of technology), and overall coordination of content. In fact, we use these meetings to help ensure that students receive consistent instruction, and that there are clear points of integration and coordination across Competencies and Modules.

While we would love to report that all these meetings and efforts to coordinate have created a program with a seamless flow, we continue to face challenges on these issues. In part due to the rapid growth of the program, further complicated by the challenge of getting new faculty up to speed on our unique approach, we are still working out this difficult balance of creativity and consistency.

What we have discovered, however, is that once the major hurdles of coordination and faculty transition to this new model have been addressed, most of the faculty really enjoy the increased collaboration. Many have noted how nice it is to work at a school and for a program where faculty have regular interaction to discuss curriculum, teaching 
methods, learning objectives, course assignments, and related issues. These regular conversations provide renewal and insights that keep our faculty engaged and our program in a state of continuous improvement.

\subsection{Constructive Critique and Revision}

These regular conversations among faculty have highlighted another important element of successful implementation of innovative curricula: the need for ongoing constructive critique and revision. While faculty in all settings are likely to periodically review their course objectives, content, materials, and delivery, our unique MBA program and regular faculty interactions make this an ongoing conversation. What we have learned is that faculty need to "check their egos at the door" when we have our meetings. We make it clear to all faculty that teach in the program that our collaborative approach will require some compromise, and likely result in occasional challenges to selected readings, activities, assignments, and teaching methods. For some faculty, this is a new experience and takes some time to adjust.

It should be noted, however, that in our experience most faculty truly welcome the increased dialogue about teaching and teaching methods. Faculty that have worked under more standard approaches find the interactive, challenging environment a refreshing change from the isolation of less collaborative approaches. This approach also seems to help in our recruitment and hiring of new faculty, who seem genuinely interested in working in these ways.

Over the first few years of the program, we created a culture where faculty members are open to and comfortable with regular review of their teaching. In our meetings of faculty within each Module and Competency, student feedback is regularly shared, and we use this feedback to guide many of our discussions. These conversations resulted in significant program refinements just two years after launch, based on the most common concerns heard from students. These changes are reflected in the table provide in Appendix C, and discussed in more detail below.

\subsection{Integrating Faculty and Staff in Planning}

Ongoing efforts to refine the program have not been guided by faculty alone. What has become clear is that the unique design and delivery of the MBA program requires more consistent and regular dialogue among faculty and staff. Since curriculum design and delivery impact both faculty members and staff, both groups must be included in discussions of curriculum design and course delivery.

Early design and launch of the program helped to create culture of faculty and staff interaction and collaboration. Our regular meetings included both faculty and staff, and all parties were encouraged to voice their concerns and suggestions on design and delivery. Indeed, the launching of our innovative program has highlighted the inseparability of design and delivery.

The specific issues we had to work through are listed in the Background / Context section of this report. The reader will note that many of these issues / concerns related to the administration of the program. From registration processes, to accounting for faculty teaching loads, to financial aid and other critical processes, the innovative curriculum did not fit within existing policies and procedures. Given the number of offices involved in adapting policies and procedures, our planning team needed to include members of the University community that may not be generally involved in curriculum design. We were fortunate to have many able and adaptable professional staff to assist us, and put up with our ongoing needs, as we both implemented and then later refined the program.

\section{Feedback and Program Revision}

\subsection{Making Changes along the Way}

It has been several years since the program was launched. And, while the initial interest and enrollment in the program surpassed even our own optimistic projections, we have also experienced many challenges and received a great deal of student feedback. Many of these challenges and feedback were addressed through minor, incremental adjustments to the content and delivery of each of the core Modules of the program, including changes in readings and assignments. More significant changes were made to address content and assignment overlap, student administrative processes, and faculty communication and coordination (since students were often confused about requirements, or received different instructions from different sources on similar issues and concerns).

One of the changes we felt compelled to make was to eliminate mandatory, full-day workshops that had been offered on Saturdays at different points in the program. While the feedback on the content and delivery of these workshops was positive overall, the logistics and costs of offering them proved difficult. While we had communicated the Saturdays that students would need to attend up front, this did not account for the rapid growth of the program (resulting in space and staffing issues), nor did it account for students who had religious or other standing obligations 
on Saturdays. To address these concerns, but still provide the benefits that these workshops provided (focused development activities, interaction across cohorts), we have continue to offer workshops to students as professional development opportunities.

\subsection{Simplifying Curriculum over Time}

Given the feedback from students and faculty in the program, it was clear that our original program design (included in Appendix C) was in need of more significant refinement. These refinements centered around three main areas:

1. The elimination of one credit competencies. The initial design included a number of one-credit competencies that were reflective of overall course content, but created significant staffing, communication, coordination, and grading concerns. Faculty and student feedback was very clear in stating that the one-credit competencies were disruptive to program flow. In addition, assessment of students for one-credit competencies was troublesome, to put it mildly. The redesigned program included two three-credit and two two-credit competencies per Module.

2. The need to reduce overlap in some areas while introducing or increasing focus in certain areas. Student feedback from especially the fourth Module of the program indicated extensive overlap in several areas (team building, strategy, international business), plus inconsistent workload across competencies that were listed as the same credit value. We addressed this by combining some areas of study, introducing some additional competencies, and either eliminating some content or moving that content from the regular program to pre-requisite courses.

3. More systematic and consistent utilization of full-time and adjunct faculty. It was clear from student and faculty feedback that the highly varied number of credits per competency and the use of adjunct faculty for smaller credit competencies created confusion for students and inconsistencies in workload and grading. Our new approach is to utilize full-time faculty for the three-credit competencies, and industry professionals / adjunct faculty for the two-credit competencies. Student feedback on this approach has been overwhelmingly positive.

\section{Conclusion and Recommendations for Others}

At the outset, we could not have foreseen the overwhelmingly positive interest in our program. Our initial forecasts for enrollment were far surpassed, and the growth of the faculty and School was tremendous. It was very rewarding. However, this great success did come with heightened expectations regarding future enrollment and program delivery. This has presented ongoing challenges as the market for MBA programs continues to change. Plus, the "newness" of the program is no longer acceptable reasoning for limitations and critiques of the program.

For colleagues at other institutions who are considering or are in the early stages of developing or implementing innovative curricula, we modestly offer the following suggestions based on our experiences:

1. Be sure to conduct a thorough examination of your major competitors to your new program. Finding ways to carve out a clear niche that students and employers can use to easily differentiate you from others will be critical in launching the program. It prevents you from having to directly compete with others, and allows your marketing to be more focused and enticing.

2. Ensure that your innovative approach fits the needs of your local market. As discussed above, learning and logistics and inexorably intertwined in professional education. Even minor inconveniences can deter potential students from enrolling in your program.

3. Get wide-spread faculty involvement and buy-in to the new program. While we benefited from starting out with a small faculty and then hiring many new faculty members, innovative curricula are disruptive to existing norms regarding teaching loads, faculty collaboration, and collaboration among faculty and staff.

4. Clear conceptual frameworks and unifying themes throughout the program will help guide program development, and assist in getting both faculty and prospective students interested and excited about the program.

5. Make friends with the people who help recruit and administer your programs. Innovative curricula will impact staff in enrollment management, registration, student records, financial aid, and international student affairs (and possibly others). You need these people as your allies to be successful in implementing and delivery your innovative program. 
6. Expect that you will need to make program refinements an ongoing part of your responsibilities. Innovative curricula are labor intensive, and require a great deal of committee work and meetings. Be sure to schedule regular meetings of faculty, staff, and administration as you design, launch, and refine the program.

\section{References}

AACSB International, Alliance for Management Education Task Force (2006). Business and Business Schools: A Partnership for the Future. AACSB International.

Chew, E.B., \& McInnis-Bowers, C. (2004). Blending Liberal Art \& Business Education. Liberal Education, 90, 56-63.

Clark, E. (2005). Designing and Implementing an Integrated Curriculum. Retrieved from https://great-ideas.org/ClarkPS.pdf

Datar, S.M., Garvin, D.A., \& Cullen, P.G. (2010). Rethinking the MBA: Business Education at a Crossroads. Harvard Business Press.

Ducoff, S.J.S., Tromley, C.L., \& Tucker, M. (2006). Interdisciplinary, Team-taught, Undergraduate Business Courses: The Impact of Integration. Journal of Management Education, 30(2), 276-294. http://dx.doi.org/10.1177/1052562905284663

Dvorak, P. (2007). MBA Programs Hone 'Soft Skills.' Wall Street Journal. Retrieved February 12, 2007 from http://wsj.com

Ewers, J. (2008). Is the MBA obsolete? U.S. News \& World Report, Special Report on America's Best Graduate Schools, 138(10), 50-52.

Fisher, A. (2007). The Trouble with MBA's. Fortune Magazine, 155(8), 49-50. Retrieved from $\mathrm{http}: / /$ money.cnn.com/magazines/fortune

Graduate Management Admissions Council (2005). MBA Program Directors Urged to Beware of "Discontinuous Shifts" in the Marketplace. Retrieved from www.gmac.com/gmac/newscenter/newscommentary/discontinuousshifts.com

Malekzadeh, A.R. (1998). Diversity, Integration, Globalization, and Critical Thinking in the Upper Division. Journal of Management Education, 22(5), 590-603. http://dx.doi.org/10.1177/105256299802200503

Mintzberg, H. (2005). Managers Not MBA's: A Hard Look at the Soft Practice of Managing and Management Development. San Francisco: Berrett-Koehler.

Navarro, P. (2008). The MBA Core Curricula of Top-Ranked U.S. Business Schools: A Study in Failure? Academy of Management Learning \& Education, 7(1), 108-123. http://dx.doi.org/10.5465/AMLE.2008.31413868

Peters, K. (2006). The Four Stages of Management Education. BizEd, 5, 36-40.

Pfeffer, J., \& Fong, C.T. (2002). The End of Business Schools? Less Success Than Meets the Eye. Academy of Management Learning and Education, 1, 78-95. http://dx.doi.org/10.5465/AMLE.2002.7373679

Rubin, S.R., \& Dierdorff, E.C. (2009). How Relevant is the MBA? Assessing the Alignment of Required Curricula and Required Managerial Competencies. Academy of Management Learning \& Education, 8(2), 208-224. http://dx.doi.org/10.5465/AMLE.2009.41788843

\section{Appendix A - Schools Reviewed in Designing Curriculum and Delivery:}

In reviewing innovative programs for design and delivery ideas, the following schools and programs were particularly useful and insightful. While we reviewed a more extensive list of schools, including the other MBA programs in the region, the schools listed below provided the most influential guidance in designing the innovative curriculum of the MBA program. We would like to thank these schools for their innovation and creativity in management education.

Babson College, Fast Track / Intel MBA Program

Baylor University, MBA Program

Boston University School of Management, Executive MBA Program

Brunel University West London, MBA Program 
City University London, Cass Business School, Modular EMBA Program

Cornell University, The Johnson School, Executive MBA Program

Drake University, MBA Program

Henley Management College, Executive Modular MBA Program

Purdue University, Krannert School of Management, Executive Master's of Business Program

University of Alberta School of Business, Management Essentials Program

University of Bath School of Management, MBA Programs

University of California, Berkeley, Haas School of Business, MBA Programs

University of Western Ontario, Richard Ivey School of Business, MBA Program

Yale School of Management, Full-time and Executive MBA Programs

\section{Appendix B - Brief overview of Program / Modules:}

The curriculum had four main modules, plus built-in flexibility to allow students to customize their studies according to their interests and professions. The four core modules of the MBA included:

1. Leading People with Integrity and Purpose - Developing the leadership skills needed to harness and direct the energies of people within an organization and its environment. Emphasis on integration of concepts from Management, Leadership, Managerial Communication, Human Resource Management, Organizational Behavior, Teamwork, and Organizational Change.

2. Managing and Leveraging Organizational Finances and Operations -Developing the analytical, forecasting and budgeting skills needed to effectively utilize and streamline organizational resources. Emphasis on integration of concepts from Managerial Accounting, Managerial Finance, Operations Management, Quantitative Business Analysis, and Quality Improvement.

3. Understanding External Environments for Long-term Success - Developing the knowledge and skills needed to manage external realities and successfully compete in market and non-market environments. Emphasis on integration of concepts from Legal and Political Environments of Business, Corporate Social Responsibility, Global Markets, Marketing Management and Branding, and International Economics.

4. Strategic and Entrepreneurial Management - Developing the skills needed to effectively and efficiently steer organizations through long-term success and growth. Emphasis on integration of concepts from Strategic Planning, Managing Organizational Growth and Development, Managing Innovation and Creativity, Leadership Development and Succession Planning, and Information Systems Design.

\section{Appendix C - Module Competencies - Original and Redesigned:}

Module 1 - Leading People with Integrity and Purpose

\begin{tabular}{|lc|lc|}
\hline Management \& Organizational Behavior & $(5)$ & Mgt. \& Org. Behavior & $(3)$ \\
\hline Leadership Skills Development & $(2)$ & Leadership Skills Development & $(3)$ \\
\hline Multicultural Communication & $(1)$ & Human Resource Management & $(2)$ \\
\hline Management Ethics & $(1)$ & & \\
\hline Business Process Management - People & $(1)$ & Project Management & $(2)$ \\
\hline
\end{tabular}

Module 2 - Managing and Leveraging Organizational Finances and Operations

\begin{tabular}{|lc|lc|}
\hline Managerial Accounting & $(3)$ & Accounting (Managerial) & $(3)$ \\
\hline Managerial Finance & $(2)$ & Finance (Managerial \& Corporate) & $(3)$ \\
\hline Managerial Economics & $(2)$ & Managerial Economics & $(2)$ \\
\hline Quantitative Decision Making & $(2)$ & & \\
\hline Business Process Mgt. - Operations & $(1)$ & Business Process Mgt. - Operations & $(2)$ \\
\hline
\end{tabular}


Module 3 - Understanding External Environments for Long-term Success

\begin{tabular}{|lc|lc|}
\hline Marketing Management & (3) & Marketing Management & $(3)$ \\
\hline Managing the Global Marketplace & $(3)$ & Managing the Global Marketplace & $(3)$ \\
\hline Business Law \& Ethics & $(2)$ & Business Law \& Regulatory Env. & $(2)$ \\
\hline International Financial Management & $(1)$ & Social Responsibility \& Sustainability & $(2)$ \\
\hline Mergers \& Acquisitions & $(1)$ & & \\
\hline
\end{tabular}

Module 4 - Strategic and Entrepreneurial Management

\begin{tabular}{|lc|lc|}
\hline Strategic Management & (3) & Strategy Design \& Implementation & (3) \\
\hline Business Process Mgt. - Strategy & $(3)$ & & \\
\hline Team Building \& Negotiation & $(2)$ & Capstone Project & $(3)$ \\
\hline Global Strategy & $(1)$ & Mergers \& Acquisitions & $(2)$ \\
\hline Social Responsibility & $(1)$ & Change Leadership & $(2)$ \\
\hline
\end{tabular}

(\#) - indicates number of credits earned for each Competency

Original program design is listed on the left, redesigned program on the right 